\title{
A razoável duração do processo penal: perspectivas a partir da circulação de modelos jurídicos
}

\author{
The reasonable duration of the criminal process: perspectives \\ from the circulation of legal models
}

\author{
Márcio Ricardo Staffen ${ }^{1}$ \\ Gustavo Polis ${ }^{2}$ \\ Lucas da Silva Santos ${ }^{3}$
}

\begin{abstract}
RESUMO:
O estudo ora proposto possui como escopo central analisar o direito fundamental a razoável duração do processo, em especial, na seara do Direito Penal e Processual Penal, bem como seu surgimento no ordenamento jurídico brasileiro. Assim, o problema de pesquisa parte das seguintes indagações: A ideia de razoável duração no processo penal brasileiro é consequência direta do emprego da circulação de modelos jurídicos? Quais são os desafios em efetivar esse Direito Fundamental no processo penal brasileiro? Posto isso, toma-se como método de abordagem o dedutivo, ao lado deste adiciona-se o método de procedimento monográfico, e por fim a técnica de pesquisa da documentação indireta. Tem-se como objetivo demonstrar a relação da circulação de modelos jurídicos com a adoção da ideia de um processo com duração razoável no Direito brasileiro, especialmente no âmbito processual penal. A hipótese de pesquisa é a de que o ordenamento jurídico brasileiro, fazendo uso da circulação de modelos jurídicos, adotou a ideia europeia de razoável duração do processo como direito fundamental, culminando com sua positivação na Constituição Federal de 1988.
\end{abstract}

PALAVRAS-CHAVE:

Razoável Duração do Processo - Acesso à Justiça - Direitos Fundamentais - Direito Processual Penal.

\footnotetext{
ABSTRACT:

The present study seeks to analyze the fundamental right to a reasonable length of the process, especially in the area of Criminal Law, as well as its emergence in the Brazilian legal system. The research problem to be faced here is: Is the idea of reasonable duration in the Brazilian

${ }^{1}$ Doutor em Direito Público pela Università degli Studi di Perugia - Itália. Doutor e Mestre em Ciência Jurídica pela Universidade do Vale do Itajaí - UNIVALI. Estágio de Pós-Doutorado em Direito junto à Università degli Studi di Perugia (Bolsa CAPES/PDE 88881.120155/2016.1). Professor Permanente no Programa de PósGraduação Stricto Sensu em Ciência Jurídica (Mestrado e Doutorado) - Universidade do Vale do Itajaí (Conceito CAPES 6).

${ }^{2}$ Mestrando em Direito na Faculdade Meridional - IMED. Bolsista CAPES/PROSUP. Bolsista de iniciação científica PROBIC/FAPERGS (2016/2017 e 2017/2018).
} 
criminal procedure a direct consequence of the use of the circulation of legal models? Using the deductive method of research, based on research and bibliographical analyzes, the objective is to demonstrate the relation of the circulation of legal models with the adoption of the idea of a process with reasonable duration in Brazilian Law, especially in the criminal procedural scope. The hypothesis of research is that the Brazilian legal system, using the circulation of legal models, adopted the European idea of reasonable duration of the process as a fundamental right, culminating with its positivation in the Federal Constitution of 1988.

\section{KEYWORDS:}

Reasonable Duration of the Process - Access to justice - Criminal proceedings - European Court of Human Rights - Circulation of Legal Models - Constitutional Amendment 45. 


\section{INTRODUÇÃO}

O presente artigo buscará discorrer sobre o direito a razoável duração do processo, em especial, no âmbito do Direito Penal e Processual Penal, bem como sua construção no sistema normativo brasileiro. A problemática proposta é: A ideia de razoável duração no processo penal brasileiro é consequência direta do emprego da circulação de modelos jurídicos? Lançando mão do método dedutivo de pesquisa, baseado em pesquisa e análises bibliográficas, tem-se como objetivo demonstrar a relação da circulação de modelos jurídicos com a adoção da ideia de um processo com duração razoável no Direito brasileiro, especialmente na seara processual penal. A hipótese de pesquisa é a de que o ordenamento jurídico brasileiro, fazendo uso da circulação de modelos jurídicos, adotou a ideia europeia de razoável duração do processo como direito fundamental, culminando com sua positivação na Constituição Federal de 1988.

Inicialmente, abordar-se-á os desdobramentos do fenômeno da globalização na esfera do Direito. Com maior ênfase, será demonstrado como a aproximação cultura/jurídica entre as diferentes nações dos planetas proporcionou a possibilidade da realização de um intercâmbio jurídico entre os diferentes ordenamentos, por meio da lógica da circulação de modelos jurídicos, distanciando o Direito do seu conceito mais usual, atrelado exclusivamente aos desígnios dos Estados Nacionais.

Partindo dessa perspectiva, tratar-se-á acerca da recepção da ideia de razoável duração do processo no direito brasileiro. Utilizando-se da circulação de modelos jurídicos, através da aprovação da Emenda Constitucional número, o ordenamento jurídico brasileiro adotou, com status de direito fundamental, as bases da razoável duração do processo nos moldes daquilo estabelecido pela Corte Europeia de Direito Humanos.

Por fim, objetiva-se compreender o direito à razoável duração do processo penal, tendo em vista, que busca-se discutir a difícil coexistência entre um processo célere que esteja em consonância com os princípios constitucionais: Acesso à Justiça, segurança jurídica e o devido processo legal. Outro aspecto de detalhamento é enfatizar as diferenças entre o tempo compreendido para quem está dentro da relação processual, para o tempo de quem está afastado da relação. Além da análise dos dados do Relatório Justiça em Número 2018 do Conselho Nacional de Justiça, que apresenta um retrato do Poder Judiciário em âmbito nacional. 


\section{A CIRCULAÇÃO DE MODELOS JURÍDICOS}

A produção do Direito, nas formas e moldes comumente aceitos pelos juristas, leia-se um Direito como produto oriundo da soberania estatal absoluta, bem como fruto das ideias imperantes dentro de determinadas fronteiras territoriais, está sendo colocada em cheque. Instalou-se, assim, um cenário de grande tensão institucional, onde as antigas instituições do Estado e os indivíduos depararam-se com uma sensação de profunda insegurança. Por assim dizer, a força motriz do Direito já não mais são anseios de limitação jurídica dos poderes estatais absolutos, mas a regulação de dinâmicas policêntricas atreladas diretamente com a circulação de modelos, capitais, pessoas e instituições distribuídos tanto em espaços físicos como nos virtuais ${ }^{4}$.

Sob a perspectiva de um mundo globalizado/transnacionalizado, as relações sociais operacionalizam-se nos diferentes segmentos societários de forma distinta daquilo que ocorria até meados do século passado ${ }^{5}$. A lógica desse fato social, e suas respectivas nuances, vêm sendo realizada através da substituição da política pelas relações de mercado, fazendo com que se imponha ao Direito algumas funções distintas daquelas até então desempenhadas por ele.

Por esse motivo a ciência jurídica se descola do velho modelo de Direito hierarquizado, e passa a exigir deste, em contrapartida, uma infindável adaptação à estrutura estabelecida, a qual, por sua vez, é caracterizada pela horizontalidade, não mais pela verticalidade, no sentido de movimentos descentralizadores e fragmentadores de poder. Isso significa dizer que os inúmeros polos de produção normativa estão esparsamente distribuídos, podendo-se, da mesma forma, observar a existência de uma pluralidade de ordenamentos jurídicos que se comunicam linearmente entre $\mathrm{si}^{6}$.

Desse modo, é fundamental pontuar que a inserção do Direito nessa nova forma de organização social, marcada por relações policêntricas, necessita de mecanismos capazes de fomentar a colaboração e, principalmente, a cooperação entre as diferentes ordens legislativas no intuito de colocar em prática mecanismos adequados para as demandas provenientes da sociedade globalizada. Tais mecanismos devem provir da inserção de uma multilateralidade,

4 STAFFEN, Márcio Ricardo. Interfaces do Direito Global. Rio de Janeiro: Lumen Juris, 2015. p. 34.

5 LOPES, Carla Patrícia Frade Nogueira. Internacionalização do Direito e Pluralismo Jurídico: Limites de Cooperação no Diálogo de Juízes. Revista de Direito Internacional, Brasília, v. 9, n. 4, p.229-247, jan. 2013. p. 231.

6 FARIA, José Eduardo. O direito na economia globalizada. São Paulo: Malheiros, 2000. p. 7. 
característica de uma ordem transnacional, no âmago do sistema jurídico nacional, como um estrato de vontades direcionadas a interesses em comum, de modo a desincumbir a produção jurídica de formas estáticas previamente fixadas, assumindo um caráter dinâmico e reflexivo ${ }^{7}$.

Na obra “Os Juízes na Mundialização: A Nova Revolução do Direito”, Julie Allard e Antoine Garapon comparam este cenário não hierárquico e policêntrico a uma espécie de rede. Essa rede, para os autores, seria pautada pela perda do papel organizador por parte do legislador e pelo constante diálogo entre os mais diversos estamentos jurídicos e suas diferentes linguagens ${ }^{8}$.

Compreendendo esta rede como um substitutivo para a clássica ideia de sistema normativo, o chamado "comércio entre juízes" cria, em certa medida, uma regularidade e previsibilidade para esse intercâmbio, Afinal, ao negar a existência de qualquer justaposição entre um e outro ordenamento, produz uma relação, como já mencionado, horizontalizada, onde todos os atores desse cenário partilham de uma tarefa e função em comum, que é a construção de um modelo de Direito capaz de dar as respostas necessárias para a sociedade plural e transnacional, baseando-se, principalmente, em uma concepção ampla de direitos humanos ${ }^{9}$. Mesmo sendo assimilado como um meio informal de produção normativa, a falta de hierarquia e acefalia constituem as bases para o funcionamento dessa circulação.

Pode-se afirmar que a circulação de modelos jurídicos se configura em uma dimensão funcionalista, ao passo que é necessário acompanhar a constante mutação do panorama mundial, adotando-se para esse fim um direito mais fluído quando os objetos de análise por parte deste também o sejam. Como exemplo dessas questões pode-se anotar o problema das novas ondas migratórias espraiadas pelos continentes europeu, sul-americano e africano, as questões envolvendo o espaço cibernético, bem como aquilo que diz respeitos aos direitos humanos e fundamentais, sejam estes de matiz privada, como a liberdade de expressão, sejam de matiz pública, como as garantias e direitos processuais.

Os pioneiros no emprego dessa relação de troca entre diferentes ordens normativas são os Estados europeus, vide a forte atuação da União Europeia através da difusão da jurisprudência de seus tribunais. Outrossim, desenvolvem-se experiências desse intercâmbio

7LOPES, Carla Patrícia Frade Nogueira. Internacionalização do Direito e Pluralismo Jurídico: Limites de Cooperação no Diálogo de Juízes. Revista de Direito Internacional, Brasília, v. 9, n. 4, p.229-247, jan. 2013. p. 233.

8ALLARD, Julie; GARAPON, Antoine. Os Juízes na Mundialização: A Nova Revolução do Direito. Tradução de: Rogério Alves. Lisboa: Instituto Piaget, 2006, p. 32.

9SIMÓN, Farith. Globalización, pluralismo jurídico y derechos humanos. Revista del Colegio de Jurisprudencia, Quito, v. 15, p.7-10, 15 jan. 2013. p. 8. 
em âmbito latino-americano, a medida que várias reformas jurídicas, em especial no direito penal, ocorreram em virtude da atuação permanente de juristas argentinos do INECIP Instituto de Estudiosos das Ciências Penais e Sociais - e promovidas, de igual sorte, por agências de cooperação americanas, no sentido de estabelecer um sistema de cunho acusatório de tipo anglo-saxônico ${ }^{10}$.

Nesta mesma linha, cabe salientar o papel central desempenhado pelo Estatuto da Criança e do Adolescente brasileiro na disseminação das legislações similares ao redor do continente, influenciando todas as discussões acerca do dever estatal de proteção da população nessa faixa etária, o qual foi tomado como exemplo por diferentes nações vizinhas para a construção de suas próprias legislações com vista a garantia dos direitos das crianças e adolescentes.

Por isso é acertada a pretensão afirmativa de que a mundialização do Direito não se limita a pôr frente a frente diferentes Direitos nacionais, porém, esta vai além e coloca em voga uma disputa entre diferentes culturas ${ }^{11}$. O ponto fundamental não é produzir provas no sentido de este ou aquele Direito ser ou não melhor, mas sim difundir esta ou aquela cultura.

A busca por jurisprudências e entendimentos estrangeiros, a avaliação permanente e concomitante entre os diferentes sistemas jurídicos são fatores que vêm alterar não somente o conceito geral do Direito, mas também desestabilizam os seus modos de produção e de reprodução. Esse cenário desintegra a coabitação, até então indivisível, entre Direito, legislador e território nacional, por esse motivo, todos os entendimentos que os modelos jurídicos possuem de si mesmos encontram-se desordenados ${ }^{12}$.

A partir do próximo tópico passa-se a analisar a forma como a circulação de modelos jurídicos está presente no Brasil. Para isso, analisar-se-á a construção da ideia de razoável duração do processo trazida pela Emenda Constitucional 45, advinda do conceito sobre a matéria previamente elaborado pela Corte Europeia de Direitos Humanos.

\section{A RECEPÇÃO DA IDEIA DE RAZOÁVEL DURAÇÃO DO PROCESSO ADVINDA DA CORTE EUROPEIA DE DIREITOS HUMANOS NO DIREITO BRASILEIRO}

10 ALLARD, Julie; GARAPON, Antoine. Os Juízes na Mundialização: A Nova Revolução do Direito, p. 
A provisão de um compromisso com a prestação jurisdicional em tempo razoável, descrita pela Convenção Europeia de Direitos Humanos, firmada em meados dos anos de 1950, e, ulteriormente, instrumentalizada pela Corte Europeia de Direitos Humanos foi fundamental para a adoção de forma expressa desse mesmo objetivo no ordenamento jurídico brasileiro. Através da Emenda Constitucional no 45, de 2004, com a introdução do inciso LXXVII no artigo $5^{\circ}$ da Carta Magna ${ }^{13}$, elevou-se a celeridade processual a norma de nível constitucional, de matiz garantista.

Levando em consideração a dificuldade em estabelecer um conceito aberto para o que, de fato, é uma razoável duração do processo e quando esta está sendo violada, a Corte Europeia de Direitos Humanos adotou a doutrina do "não-prazo"14, através da qual efetua análises de casos particulares em sua concretude. Portanto, de caso em caso, de acordo com determinadas circunstâncias, porém de forma global, a Corte considera que alguns aspectos do processo devem ser levados em conta com mais cuidado para que se chegue a um consenso de violação ou não a um período razoável para a resposta judiciaria.

Tal análise é feita sempre levando em conta alguns aspectos primordiais: a) se os atrasos, que sozinhos não seriam reprováveis, juntos podem ultrapassar um prazo razoável de resposta; b) o atraso em uma determinada fase pode até ser admitido, desde que o conjunto do procedimento não ultrapasse a razoabilidade; c) longos períodos de estagnação sem motivação não são tolerados. A partir desses postulados, pode-se buscar a apreciação correta acerca das demandas concernentes a celeridade dos trâmites processuais, segundo a $\mathrm{CEDH}^{15}$.

Caso reconhecida uma exacerbada delonga no trâmite processual, a Corte passa à análise da razoabilidade do prazo de duração. Para isso, faz uso de alguns parâmetros objetivos de aferição, tais como: a) a complexidade da causa, relacionado com as diversidades procedimentais e as expectativas das partes; b) o comportamento das partes e de seus respectivos procuradores, questão que diz respeito os abusos dos direitos processuais; c) o cenário em que o processo transcorreu; d) a atuação das autoridades judiciais, ligada especialmente ao exercício de poder por parte dos juízes para dar andamento célere ao processo; e) a relevância do litígio para os demandantes ${ }^{16}$.

13 Constituição Federal Brasileira de 1988, artigo 5, inciso LXXVIII:“a todos, no âmbito judicial e administrativo, são assegurados a razoável duração do processo e os meios que garantam a celeridade de sua tramitação.

14 NICOLAU, Nara Benedetti. Duração Razoável do Processo no Direito Europeu. Revista Custos Legis, Rio de Janeiro, jun. 2011.

15 Idem.

16 Idem. 
Partindo dos conceitos delineados pela CEDH acerca da razoável duração do processo, denota-se a iminente vontade do legislador brasileiro em melhorar a qualidade da prestação jurisdicional no tocante a lentidão do aparato judicial ${ }^{17}$. Essa pretensão é cristalina quando da análise da exposição de motivos para a promulgação da Emenda Constitucional 45, e suas respectivas propostas de modernização do Poder Judiciário brasileiro, responsável pela adição do inciso LXXVIII ao artigo $5^{\circ}$ da Carta Constitucional.

Nesse sentido, visando esclarecer naquele momento histórico as razões pelas quais se fazia necessário realizar amplas reformas na estrutura judiciária, os parlamentares responsáveis pelo projeto da referida Emenda Constitucional na Câmara dos Deputados, encabeçados pelo seu relator Hélio Bicudo, elaboraram uma notória exposição de motivos documento confeccionado pelas casas legislativas quando da promulgação de qualquer dispositivo legal - onde descreverem, pormenorizadamente, a história do Poder Judiciário no Brasil, expondo as mazelas a ele inerentes, bem como a urgência de seu aperfeiçoamento.

O relatório inicia traçando um paradoxo entre os diferentes modelos jurídicos que imperaram no território nacional. Em um primeiro instante aborda a estrutura do sistema durante a vigência do Império, particularmente a expansão das cortes judiciais com o advento da Constituição de 1824, a qual, a seu turno, também foi responsável pela criação de um Supremo Tribunal de Justiça ${ }^{18}$ como instância recursal máxima para todo o país, antes espalhada em apenas três cidades, Rio de Janeiro, São Luiz do Maranhão e Salvador.

Seguindo, a exposição de motivos realça o conturbado início da República e os efeitos no Poder Judiciário. No modelo da Constituição Federal de 1891, o Supremo Tribunal Federal passou a ser o detento do poder de dizer a constitucionalidade das leis, passando a atuar como um vigilante da legalidade, supervisionando os demais poderes. Na Primeira República a justiça cindiu-se em dois polos principais: o federal e o estadual. Por outro lado, as Constituições de 1934, 1937 e 1946 não trouxeram grandes mudanças, a não ser a concessão da capacidade de os tribunais elaborarem seus respectivos regimentos internos ${ }^{19}$.

Após o apanhado histórico, o texto chega aos problemas enfrentados pela administração da justiça naquele determinado momento da história. Traz a ideia do difícil

17 MOLOGNI, Celina Kazuko Fujioka; PIEROTTI, Sara Mendes. Do Direito à Razoável Duração do Processo: necessidade de se equacionar o processo célere com as garantias de defesas mínimas. Revista do Direito Privado, Londrina, v. 3, n. 1, abr. 2010.

18 DEPUTADOS, Câmara dos. Exposição de Motivos - Emenda Constitucional No 45. 2004. Disponível em: <http://www2.camara.leg.br/legin/fed/emecon/2004/emendaconstitucional-45-8-dezembro-2004-535274exposicaodemotivos-149264-pl.html>. Acesso em: 14 set. 2018.

19 Idem. 
período que o Poder Judiciário foi posto durante a vigência do regime militar, responsável, em grande parte, por um engessamento do sistema, impedindo-o de se desenvolver da forma necessária ${ }^{20}$.

A timidez com que o governo brasileiro vinha, até então, atentando à urgência da modernização do aparelhamento judicial tinha sido, sem dúvidas, a causa da avassaladora crise em que há muitos anos se abatia sobre a justiça. Salientou, ainda, que a justiça era quase sempre tardia, deixando de dar provimento as demandas das partes de uma forma satisfatória e em tempo razoável, sendo isso um reflexo da defasagem dos $\operatorname{Poder}^{21}$, representado por seus Órgãos, que, em função disso, negligenciavam constantemente todo o elenco de direitos humanos em contraposição a diversas garantias da Carta Maior.

Diagnosticou-se a inquestionável necessidade de uma ampla reforma judiciária, por meio de uma atualização completa do sistema. Nesse cenário, no intuito de refrigerar e modernizar os meios judiciais existentes à época, procurando remediar alguns de seus problemas, procedeu-se a aglutinação de construções acerca do funcionamento da justiça elaboradas por outras nações ao sistema brasileiro, tal qual a ideia de celeridade processual advinda do conceito da CEDH, face o empecilho a efetivação de uma gama considerável de direitos em razão da exacerbada morosidade dos procedimentos judiciais ${ }^{22}$.

Exemplo dessa busca pelo modelo europeu na questão da celeridade são as indicações elaboradas pelo Banco Interamericano de Desenvolvimento à época, através de diversos relatórios, para o Poder Judiciário brasileiro. Tais documentos apontavam a evidente falta de estrutura do judiciário, seja material ou de pessoal, como a principal causa do retardamento dos feitos judiciais no Brasil, sendo seguidas por uma dificuldade em promover em tempo razoável as citações e intimações necessárias ao seguimento dos atos processuais, o longo período para a apresentação dos laudos periciais e a mora por parte dos próprios demandantes do processo $^{23}$.

Imperioso ressaltar nesse ponto, a forte pressão exercida por diversos agentes externos, tal qual o BID, para que o Brasil adota-se medidas mais sofisticadas no sentido de garantir a prestação da tutela jurisdicional, nos moldes europeus, por meio do emprego de uma circulação de modelos jurídicos, sob pena de inviabilizar um número expressivo de

\footnotetext{
20 Idem.

21 Idem.

22 DEPUTADOS, Câmara dos. Exposição de Motivos - Emenda Constitucional No 45. 2004

23 ROSA, Edgard Lincoln de Proença. Poder Judiciário no Brasil: Aspectos de sua Reforma. Revista de Informação Legislativa, Brasília, v. 40, n. 158, p.23-70, abr. 2003.
} 
investimentos nas mais diversas áreas do país ${ }^{24}$, em função da descrença e desconfiança que até então pairavam sobre o sistema jurídico brasileiro por parte do poder econômico transnacional.

Com a aprovação da Emenda Constitucional 45, no ano de 2004, reconheceu-se a razoável duração do processo como um direito fundamental de todos os cidadãos constitucionalmente garantido. Leva-se em consideração no âmbito da proteção judicial efetiva, inspirado nas ideias da CEDH, que a duração indefinida dos processos fere a ideia de proteção aos direitos fundamentais, já que a duração excessivamente prolongada dos procedimentos judiciais afeta não apenas a proteção judicial, mas compromete, de modo incisivo, a proteção da dignidade da pessoa humana, na medida em que pode equiparar os cidadãos a objetos, os deixando à mercê de incertezas processuais acerca de seus direitos positivados 25 .

Por conseguinte, o direito à prestação jurídica célere e eficaz é direito de todos, indistintamente, servindo como meio de erradicar eventuais más prestações do poder estatal para com os seus cidadãos ${ }^{26}$, tal qual extraiu-se da jurisprudência europeia, disponibilizada, em sua imensa maioria, pelos entendimentos e interpretações da Convenção Europeia de Direitos Humanos pela Corte Europeia de Direitos Humanos, através da adoção da teoria da circulação de modelos jurídicos.

\section{O DIREITO DE SER JULGADO EM UM PRAZO RAZOÁVEL NO PROCESSO PENAL BRASILEIRO}

$\mathrm{Na}$ esteira do direito comunitário internacional que a partir de tratados, convenções, reconhecem a importância do direito à duração razoável do processo, esse direito encontra-se positivado na Convenção Europeia de Direitos do Homem e Convenção Americana sobre Direitos Humanos (Pacto San José da Costa Rica). Do mesmo modo, presente nas Constituições europeias: Constituição Italiana, Constituição Espanhola e Constituição

\footnotetext{
24 Idem.

25 MENDES, Gilmar Ferreira; COELHO, Inocêncio Mártires; BRANCO, Paulo Gustavo Gonet. Curso de Direito Constitucional. São Paulo: Saraiva, 2007, p. 485.

26 MOLOGNI, Celina Kazuko Fujioka; PIEROTTI, Sara Mendes. Do Direito à Razoável Duração do Processo: necessidade de se equacionar o processo célere com as garantias de defesas mínimas. Revista do Direito Privado, Londrina, v. 3, n. 1, abr. 2010.
} 
Portuguesa. A Constituição Federal Brasileira, reconhece uma razoável e célere tramitação processual como um Direito Fundamental de cláusula geral ${ }^{27}$.

Esse direito retrata o sentimento comum da coletividade, na acepção de que a Justiça é morosa e denegada para determinados grupos sociais. De modo, que assegurar à duração razoável e justa do processo, gera confiança na sociedade, que a partir disso passa a crer na prestação jurisdicional e no funcionamento das instituições públicas ${ }^{28}$.

No Direito Processual Penal, a problemática do tempo de duração do processo exige atenção especial, principalmente após a promulgação da Constituição Federal de 1988, que trouxe a compreensão coletiva acerca da titularidade de direitos e garantias individuais. Por conseguinte, tal entendimento, refletiu-se diretamente no crescimento vertiginoso de litígios levados ao Poder Judiciário ${ }^{29}$.

O Estado Democrático de Direito, unifica princípios como por exemplo o Acesso à Justiça $^{30}$ e a segurança jurídica, porém, esses princípios apenas serão atingidos se o Estado atender as demandas das partes dentro de um prazo razoável. Nessa senda, a demora jurisdicional pode refletir a fragilidade estatal, na concretização dos Direitos Fundamentais no Brasil $^{31}$.

Todavia, para que se desenvolva o processo em um prazo razoável, ou seja, para que o direito a uma Justiça tempestiva seja efetivado, especificamente no processo penal brasileiro, essa análise deve estar pautada em dois aspectos iniciais: a) o direito ao processo penal sem dilações, garantindo a presunção de inocência; b) o direito ao desencarceramento dos acusados presos cautelarmente (prisão sem pena), quando não forem julgadas em um tempo razoável ${ }^{32}$.

É fundamental determinar/fixar um prazo máximo para as medidas cautelares no Código de Processo Penal Brasileiro, esse aspecto não pode prosseguir como um critério a ser

27 SARLET, Ingo Wolfgang; MITIDIERO, Daniel; MARINONI, Luiz Guilherme. Curso de Direito Constitucional. 3 ed. São Paulo: Revista dos Tribunais, 2014, p. 765-766.

28 Idem.

29 FONSECA, Hauler dos Santos. A duração razoável do processo como expressão de respeito à dignidade da pessoa humana e sua implicação na responsabilidade do estado. Dissertação (Mestrado em Direito) - Curso de Pós-Graduação em Direito, Universidade de Lisboa, Lisboa, 2016, p. 27.

30 CAPPELLETTI explica: “ A expressão 'acesso à Justiça' é reconhecidamente de difícil definição, mas serve para determinar duas finalidades básicas do sistema jurídico - o sistema pelo qual as pessoas podem reivindicar seus direitos e/ou resolver seus litígios sob os auspícios do Estado. Primeiro, o sistema deve ser igualmente acessível a todos; segundo, ele deve produzir resultados que sejam individual e socialmente justos".

31 SCHMITT, Cristiano Heineck. Direito à razoàvel duração do processo no brasil: origens, Inobservância e tentativas de concretização. Revista do Faculdade de Direito da UFG, Goiânia, v. 34, n. 1, 2010, p. 42. 32BADARÓ, Gustavo Henrique. Processo Penal. 3 ed. São Paulo: Revista dos Tribunais, 2015,p. 69. 
definido pela discricionariedade dos julgadores. Afirma-se isso, em razão da permanente instrumentalização da prisão preventiva ${ }^{33}$, que acaba sendo eleita para determinados acusados, que assevera a finalidade estatal de adequação do processo cautelar, que resulta na relativização desse instituto cautelar, que possui como princípios a excepcionalidade e provisionalidade. A média de duração da prisão provisória em âmbito nacional oscila entre inicialmente (172) cento e setenta e dois dias e (974) novecentos e setenta e quatro dias, ou seja, podendo prisões provisórias chegar a mais de dois anos e seis meses de custódia sem condenação ${ }^{34}$.

Uma questão importante a ser ressaltada, é o fato de que no momento em que a duração de um processo excede o limite do razoável, o Estado se apodera ilegalmente do tempo do acusado/réu, e a retirada desse tempo é algo irreversível. E a partir dessa posse ilegal de sua liberdade, mesmo que não encontre-se em uma prisão cautelar, o processo por si mesmo torna-se uma verdadeira punição ${ }^{35}$

Em complemento, quando se fala no direito de ser julgado em um prazo razoávelde imediato limita-se a ideia de tempo (calendário), todavia, a complexidade dos problemas enfrentados pela sociedade contemporânea, especialmente os intrínsecos a seara processual penal, conduzem para necessidade de problematizar e ampliar a questão temporal em outras dimensões: tempo social e tempo subjetivo ${ }^{36}$.

A pena privativa de liberdade não se reduz apenas ao afastamento da liberdade individual (espaço social) do réu, o encarceramento resulta na privação da liberdade física, bem como, na estagnação no tempo social. Significa dizer que a compreensão do tempo e do espaço como sociais, não restringe-se apenas as dimensões físicas e naturais, o tempo da pena a partir dos critérios físicos se atrela a uma perspectiva de contratempo, inércia do tempo social, mesmo que não paralisado o tempo físico ${ }^{37}$.

33 Código de Processo Penal preceitua em seu artigo 312: “A prisão preventiva poderá ser decretada como garantia da ordem pública, da ordem econômica, por conveniência da instrução criminal, ou para assegurar a aplicação da lei penal, quando houver prova da existência do crime e indício suficiente de autoria".

34 BRASIL. Conselho Nacional de Justiça. Reunião Especial de Jurisdição do CNJ com os Presidentes dos Tribunais de Justiça dos $\quad$ Estados 2017.2 Disponível em:<http://www.cnj.jus.br/files/conteudo/arquivo/2017/02/b5718a7e7d6f2edee274f93861747304.pdf>. Acesso em: 03 de setembro de 2018.

35LOPES JÚNIOR, Aury. Direito Processual Penal. 11 ed. São Paulo: Saraiva, 2014, p. 123.

36LOPES JÚNIOR, Aury. O direito de ser julgado em um prazo razoável na perspectiva einsteiniana da Teoria da Relatividade. In: D’AVILA, Fabio Roberto; GIACOMOLLI, Nereu; ANTUNES, Maria João e SANTOS, Claudia Porto Alegre (Org.). Direito penal e constituição: diálogos entre Brasil e Portugal. Porto alegre: Boutique Jurídica, 2018, p. 447.

37CHIES, Luiz Antônio Bogo. A capitalização do tempo social na prisão: a remição no contexto das lutas de temporalização na pena privativa de liberdade. Tese (Doutorado em Sociologia) - Curso de Pós-Graduação em Sociologia, Universidade Federal do Rio Grande do Sul, Porto Alegre, 2006, p. 229. 
Nesse sentido, apesar das discussões presentes no Direito Penal acerca das teorias que visam justificar a pena, o certo é que a noção de sanção está atrelada a lógica retributiva (tempo de aflição) pelo dano (s) causado(s) pelo réu. Assim, a pena privativa de liberdade está fundada em um tempo fixo, em contrapartida, o tempo social é constante ${ }^{38}$.

O conflito entre o tempo absoluto do Direito e o tempo subjetivo do réu, ou seja, o caráter do tempo subjetivo e o tempo social, servem como base para mensurar as dores provocadas pela privação de liberdade, bem como, a sensação do tempo e sua influência no cotidiano do indivíduo como elementos da punição ${ }^{39}$.

Cabe ressaltar, que o direito à duração razoável do processo não pode ser submetido a um reducionismo, lógica de processo rápido/instantâneo, o procedimento (rito) processual deve ser respeitado, isto é, as etapas procedimentais não podem ser mitigadas em favor de uma aceleração. É imprescindível alcançar o equilíbrio entre uma tramitação razoável, mas que coexista com os demais direitos e garantias fundamentais.

O processo penal deve ser agilizado. Insistimos na necessidade de acelerar o tempo do processo, mas desde a perspectiva de quem o sofre, enquanto forma de abreviar o tempo de duração da pena-processo. Não se trata da aceleração utilitarista com tem sido feito, através da mera supressão de uma jurisdição de qualidade, como ocorre na justiça negociada, senão de acelerar através da diminuição da demora judicial com caráter punitivo. É diminuição de tempo burocrático (verdadeiros tempos mortos) através da inserção de tecnologia e otimização de atos cartorários e mesmo judiciais $^{40}$.

Destarte, é no procedimento judicial que se instaura o desafio: execução de um processo célere em consonância com o devido processo legal. Assegurar o contraditório e a ampla defesa, são pilares para a concretização do direito à razoável duração do processo, esses elementos devem caminhar em conjunto, para que efetivamente se compatibilize com os princípios básicos do Estado Democrático de Direito.

O desafio de efetivar uma tramitação célere (justa) no Brasil, é verificada a partir dos dados do Relatório Justiça em Números 2018, produzido pelo Conselho Nacional de Justiça $(\mathrm{CNJ})$. Esse relatório tem como escopo apresentar um retrato do Poder Judiciário Brasileiro, e por conseguinte priorizar determinadas situações processuais. Segundo o relatório, o

38LOPES JÚNIOR, Aury. O direito de ser julgado em um prazo razoável na perspectiva einsteiniana da Teoria da Relatividade, p. 451.

39CHIES, Luiz Antônio Bogo. A capitalização do tempo social na prisão: a remição no contexto das lutas de temporalização na pena privativa de liberdade, p. 242.

40 LOPES JÚNIOR, Aury. O direito de ser julgado em um prazo razoável na perspectiva einsteiniana da Teoria da Relatividade, p. 451-454. 
Judiciário Brasileiro possuía mais de (80) oitenta milhões de processos em tramitação no ano de 2017, no primeiro grau de jurisdição estão concentrados (94) noventa e quatro por cento dessa totalidade ${ }^{41}$.

No tocante a Justiça Criminal, no ano de 2017, ingressaram no Poder Judiciário pelo menos $(2,7)$ dois milhões e setecentos mil novos casos (excluídos os casos de execução penal), sendo $(1,7)$ um milhão e setecentos mil que ingressaram na fase de conhecimento $\left(1^{\circ}\right.$ grau de jurisdição). O segmento que possui maior expressão em situações de litígios é a Justiça Estadual ${ }^{42}$.

Os tempos de duração média dos processos analisados pelo Relatório Justiça em Números, são apresentados a partir de três perspectivas: o tempo médio até a sentença, o tempo médio até a baixa/arquivamento e o tempo médio dos processos pendentes na data de 31 de dezembro de 2017. Desse modo, as maiores faixas temporais estão concentradas em situações de processos pendentes: Justiça Federal (7) sete anos e (11) onze meses e da Justiça Estadual (6) seis anos e (9) nove meses. As execuções penais foram excluídas dessa análise ${ }^{43}$.

No que refere-se aos resultados de duração média dos processos baixados no ano de 2017 por tribunal, o relatório apresenta dois cenários opostos no $2^{\circ}$ grau de Jurisdição. Nas Justiças Estadual e Militar Estadual não há alteração significativa entre os tempos de baixa dos processos criminais e não criminais. Na Justiça Federal a situação se altera substancialmente, o processo não criminal demanda, pelo menos, o dobro de tempo do processo criminal; na Justiça Eleitoral ocorre a situação inversa ${ }^{44}$.

No $1^{\text {o }}$ grau de jurisdição, o tempo do processo criminal é maior que o do processo não criminal, em todas as ramificações do Poder Judiciário. Os processos relativos às execuções de privação de liberdade que foram baixados no ano de 2017, possuem a duração média de baixa de (3) três anos e (5) cinco meses na Justiça Estadual, e de (1) um ano e (5) cinco meses na Justiça Federal ${ }^{45}$.

Uma longa tramitação processual, desencadeia em uma série de consequências para as partes, familiares, vítimas e consequentemente no funcionamento do aparelho judicial. Contudo, as consequências propagam-se para sociedade, pois a demora extrema, além de

41 BRASIL. Justiça em Números 2018: ano-base 2017. Conselho Nacional de Justiça, Brasília: CNJ, $2018 . \quad$ Disponível $\quad$ em: <http://www.cnj.jus.br/files/conteudo/arquivo/2018/09/8d9faee7812d35a58cee3d92d2df2f25.pdf.>. Acesso em: 06 de novembro de 2018.

42 Idem.

43 BRASIL. Justiça em Números 2018: ano-base 2017. Conselho Nacional de Justiça, Brasília: CNJ, 2018.

44 Idem.

45 Idem. 
produzir efeitos nefastos para as partes interessadas, em conjunto, origina-se a descrença no bom funcionamento das instituições públicas.

Posto isso, no âmbito do processo penal, não existe velocidade e tampouco aceleração, as garantias fundantes do devido processo legal não podem ser objeto de atropelos, em razão da demora jurisdicional. Aliás a duração razoável do processo é um dos mais antigos e complexos problemas da administração da Justiça no mundo, porém, o direito a um processo sem dilações, inclui-se em um princípio mais amplo, o da celeridade processual, pois no Direito Processual Penal diferentemente das outras searas do Direito, o processo deve ser interpretado sob a égide da proteção constitucional do réu, posto que, celeridade processual não pode ser almejada, caso isso, promova a relativização da ampla defesa e contraditório do réu ${ }^{46}$.

No entanto, conforme expõe Amaral sobre os direitos individuais "Deparamo-nos com uma democracia jogada contra ela mesma, onde o retorno das exigências de controle, segurança e punição avançam triunfantes sobre os próprios direitos pessoais. Na medida em que os direitos do homem tornam-se uma política ${ }^{47}$."

O pressuposto da pena (castigo) não elimina a existência das garantias procedimentais, à ciência penal não possui outra razão senão verificar a necessidade da punição através do processo. Deste modo, direitos e garantias fundamentais não podem ser postos como obstáculos à segurança pública, ou ainda, sinônimos de impunidade. Assim, discursos dirigidos e construídos sob a lógica do espetáculo (sempre em nome da luta do bem e do mal), visam legitimar prisões e processos desnecessários, para agradar às maiorias de ocasião $^{48}$.

Em síntese, é de suma importância compreender as questões que envolvem tempodireito e tempo-processo. De maneira, que existe um tempo compreendido para quem está dentro da relação processual, e outro para quem está fora, o tempo subjetivo no processo penal, em que o réu/acusado, sofre diversas penas durante a tramitação processual é diferente, pois, o mesmo está sendo punido antes mesmo da resolução do processo ${ }^{49}$.

46 LOPES JÚNIOR, Aury. O direito de ser julgado em um prazo razoável na perspectiva einsteiniana da Teoria da Relatividade, p. 460.

47 AMARAL, Augusto Jobim do. A vertigem da ostentação penal. Novos Estudos Jurídicos, v. 18, n. 3, p. 500-517, 2013.

48 CASARA, Rubens. A ampliação das hipóteses da prisão preventiva: uma corrupção das conquistas civilizatórias. Boletim do Instituto Brasileiro de Ciências Criminais. São Paulo, Boletim no 277, p. 21-22, dezembro 2015.

49 LOPES JÚNIOR, Aury. O direito de ser julgado em um prazo razoável na perspectiva einsteiniana da Teoria da Relatividade, p. 464. 
O processo penal não pode ser objeto de acelerações que causem sua desnaturalização, também é necessário preocupar-se com a espetacularização do processo. Uma excessiva publicidade pode provocar danos significativos as partes, familiares e vítimas envolvidas, além disso, em situações extremas pode-se interferir na imparcialidade do julgador, que ao invés de estar comprometido com uma atuação contra majoritária, pode buscar atender os anseios punitivos da sociedade ${ }^{50}$.

Portanto, a duração na seara processual penal deve ser apreciada em consonância com o devido processo legal, é imprescindível verificar as peculiaridades de cada caso concreto. Não é possível auferir uma solução pré-estabelecida (pronta), genérica a ser utilizada em todas as situações processuais, uma vez que, deve-se reconhecer as especificidades e limites de cada situação que se apresente.

\section{CONCLUSÃO}

Por sim, conclui-se que a produção do Direito, nas formas e moldes comumente aceitos pelos juristas, um Direito como produto oriundo da soberania estatal absoluta, bem como fruto das ideias imperantes dentro de determinadas fronteiras territoriais, está sendo colocada em cheque. Instalou-se um cenário de grande tensão institucional, onde as antigas instituições do Estado e os indivíduos depararam-se com uma sensação de profunda insegurança. Desse modo, a força motriz do Direito já não mais são anseios de limitação jurídica dos poderes estatais absolutos, mas a regulação de dinâmicas policêntricas atreladas diretamente com a circulação de modelos, capitais, pessoas e instituições distribuídos tanto em espaços físicos como nos virtuais.

Em função disso, a ciência jurídica se descola do velho modelo de Direito hierarquizado, e passa a exigir deste uma infindável adaptação à estrutura estabelecida, a qual, por sua vez, é caracterizada pela horizontalidade, não mais pela verticalidade, no sentido de movimentos descentralizadores e fragmentadores de poder. Isso significa dizer que os inúmeros polos de produção normativa estão esparsamente distribuídos, podendo-se, da mesma forma, observar a existência de uma pluralidade de ordenamentos jurídicos que se comunicam linearmente entre si por meio de um movimento de circulação de modelos.

Exemplo dessa circulação de modelos jurídicos é a recepção da ideia da razoável duração do processo no ordenamento jurídico brasileiro. Com o escopo de modernizar o 
sistema judiciário brasileiro, fazendo uso da circulação de modelos jurídicos, o Brasil adotou para si os padrões de celeridade e razoável duração do processo estipulados pela Corte Europeia de Direito Humanos, culminando com a sua positivação e reconhecimento como um Direito Fundamental no artigo 5 , inciso LXXVII, da Constituição Federal de 1988, através da aprovação da Emenda Constitucional 45.

No âmbito do Direito Processual Penal, efetivar os padrões adotados de celeridade e razoável duração do processo, apresentam-se como um grande desafio, o Poder Judiciário Brasileiro, especialmente no $1^{\circ}$ grau de jurisdição está completamente sobrecarregado, os processos criminais demandam mais tempo do que os processos não criminais.

Conclui-se, que é fundamental a compreensão de que o processo penal não pode ser objeto de acelerações, isto é, a duração razoável do processo não pode ser reduzida a uma lógica de resolução instantânea, e as fases procedimentais devem estar em conformidade com o devido processo legal e demais princípios constitucionais. Por fim, assimilar a diferença entre tempo-direito e tempo-processo, além dos danos causados por uma excessiva publicidade, penas sofridas durante o processo pelas partes, que relativizam a presunção de inocência.

\section{REFERÊNCIAS BIBLIOGRÁFICAS}

ALLARD, Julie; GARAPON, Antoine. Os Juízes na Mundialização: A Nova Revolução do Direito. Tradução de: Rogério Alves. Lisboa: Instituto Piaget, 2006.

AMARAL, Augusto Jobim do. A vertigem da ostentação penal. Novos Estudos Jurídicos, v. 18 , n. 3, p. 500-517, set-dez, 2013.

BADARÓ, Gustavo Henrique. Processo Penal. 3. ed. São Paulo: Revista dos Tribunais, 2015.

BRASIL. Código de Processo Penal. Decreto Lei n³.689, de 03 de outubro de 1941. Disponível em: <http://www.planalto.gov.br/ccivil_03/decreto-lei/Del3689Compilado.htm>. Acesso em: 20 de julho de 2018.

BRASIL. Constituição da República Federativa do Brasil. 1988. Disponível em: <http://www.planalto.gov.br/ccivil_03/Constituicao/Constituicao.htm>. Acesso em: 09 de setembro de 2018.

BRASIL. Conselho Nacional de Justiça. Reunião Especial de Jurisdição do CNJ com os Presidentes dos Tribunais de Justiça dos Estados 2017. Disponível em:

<http://www.cnj.jus.br/files/conteudo/arquivo/2017/02/b5718a7e7d6f2edee274f93861747304. pdf $>$. Acesso em: 03 de setembro de 2018. 
BRASIL. Justiça em Números 2018: ano-base 2017. Conselho Nacional de Justiça, Brasília: CNJ, 2018. Disponível em:

<http://www.cnj.jus.br/files/conteudo/arquivo/2018/09/8d9faee7812d35a58cee3d92d2df2f25. pdf.>. Acesso em: 06 de novembro de 2018.

CAPPELLETTI, Mauro; GARTH, Bryant. Acesso à Justiça. Porto Alegre: Fabris, 1998.

CASARA, Rubens. A ampliação das hipóteses da prisão preventiva: uma corrupção das conquistas civilizatórias. Boletim do Instituto Brasileiro de Ciências Criminais. São Paulo, Boletim no 277, p. 21-22, dezembro 2015. Disponível em:

<http://www.ibccrim.org.br/site/boletim/pdfs/Boletim277.pdf>. Acesso em: 18 de setembro de 2018.

CHIES, Luiz Antônio Bogo. A capitalização do tempo social na prisão: a remição no contexto das lutas de temporalização na pena privativa de liberdade. Tese (Doutorado em Sociologia) - Curso de Pós-Graduação em Sociologia, Universidade Federal do Rio Grande do Sul, Porto Alegre, 2006.

DEPUTADOS, Câmara dos. Exposição de Motivos - Emenda Constitucional No 45. 2004. Disponível em: <http://www2.camara.leg.br/legin/fed/emecon/2004/emendaconstitucional45-8-dezembro-2004-535274-exposicaodemotivos-149264-pl.html>. Acesso em: 14 set. 2018 .

FARIA, José Eduardo. O direito na economia globalizada. São Paulo: Malheiros, 2000.

FONSECA, Hauler dos Santos. A duração razoável do processo como expressão de respeito à dignidade da pessoa humana e sua implicação na responsabilidade do estado. Dissertação (Mestrado em Direito) - Curso de Pós-Graduação em Direito, Universidade de Lisboa, Lisboa, 2016.

LOPES, Carla Patrícia Frade Nogueira. Internacionalização do Direito e Pluralismo Jurídico: Limites de Cooperação no Diálogo de Juízes. Revista de Direito Internacional, Brasília, v. 9, n. 4, p.229-247, jan. 2013.

LOPES JÚNIOR, Aury. Direito Processual Penal. 11 ed. São Paulo: Saraiva, 2014.

O direito de ser julgado em um prazo razoável na perspectiva einsteiniana da Teoria da Relatividade. In: D’AVILA, Fabio Roberto; GIACOMOLLI, Nereu; ANTUNES, Maria João e SANTOS, Claudia Porto Alegre (Org.). Direito penal e constituição: diálogos entre Brasil e Portugal. Porto alegre: Boutique Jurídica, p. 447-464,2018.

MENDES, Gilmar Ferreira; COELHO, Inocêncio Mártires; BRANCO, Paulo Gustavo Gonet. Curso de Direito Constitucional. São Paulo: Saraiva, 2007.

MOLOGNI, Celina Kazuko Fujioka; PIEROTTI, Sara Mendes. Do Direito à Razoável Duração do Processo: necessidade de se equacionar o processo célere com as garantias de defesas mínimas. Revista do Direito Privado, Londrina, v. 3, n. 1, abr. 2010. 
NICOLAU, Nara Benedetti. Duração Razoável do Processo no Direito Europeu. Revista Custos Legis, Rio de Janeiro, jun. 2011.

ROSA, Edgard Lincoln de Proença. Poder Judiciário no Brasil: Aspectos de sua Reforma. Revista de Informação Legislativa, Brasília, v. 40, n. 158, p.23-70, abr. 2003.

SARLET, Ingo Wolfgang; MITIDIERO, Daniel; MARINONI, Luiz Guilherme. Curso de Direito Constitucional. 3 ed. São Paulo: Revista dos Tribunais, 2014.

SCHMITT, Cristiano Heineck. Direito à razoável duração do processo no brasil: origens, Inobservância e tentativas de concretização. Revista do Faculdade de Direito da UFG, Goiânia, v. 34, n. 1, jan.-jun., 2010, p. 42.

SIMÓN, Farith. Globalización, pluralismo jurídico y derechos humanos. Revista del Colegio de Jurisprudencia, Quito, v. 15, p.7-10, 15 jan. 2013.

STAFFEN, Márcio Ricardo. Interfaces do Direito Global. Rio de Janeiro: Lumen Juris, 2015.1988.

Submetido em: 10/12/2018

Aceito em: 15/02/2019 